\title{
Persistent left superior vena cava
}

\author{
Christian S Haas MD ${ }^{1}$, Christina Doesch $\mathrm{MD}^{2}$, Volker Doernberger $\mathrm{MD}^{1}$
}

\begin{abstract}
A 76-year-old man with coronary artery disease and a history of aorA tocoronary bypass surgery seven years previously presented with symptomatic bradycardia and atrial fibrillation. After evaluation of the coronary status by cardiac catheterization, the decision was made to implant a ventricular rate responsive demand (VVIR) pacemaker. Positioning of the ventricular lead via the left subclavian vein was associated with problems while pushing the lead forward. Radiographic imaging with contrast media revealed the presence of a persistent left superior vena cava (PLSVC), with the pacemaker lead following the path of the additional vein. Using fluoroscopy, positioning of the pacemaker lead was completed without further problems. The chest $\mathrm{x}$-ray performed after the procedure showed the left-sided path of the pacemaker's lead (Figure 1), indicating the presence and path of the abnormal vein. PLSCV is the most common thoracic vein anomaly, occurring in approximately $0.5 \%$ of the normal population. It is often associated with a missing right superior vena cava or other cardiac anomalies (1), and can be detected by various methods, including echocardiography and magnetic resonance tomography (2). However, in the majority of cases, PLSCV is an incidental finding during diagnostic and therapeutic procedures $(3,4)$. Therefore, physicians should be aware of this anomaly and the associated technical problems in this setting.
\end{abstract}

\section{REFERENCES}

1. Gonzales-Juanatey C, Testa A, Vidan J, et al. Persistent left superior vena cava draining into the coronary sinus: Report of 10 cases and literature review. Clin Cardiol 2004:27:515-8.

2. Recupero A, Pugliatti P, Rizzo F, et al. Persistent left-sided superior vena cava: Integrated noninvasive diagnosis. Echocardiography 2007;24:982-6.

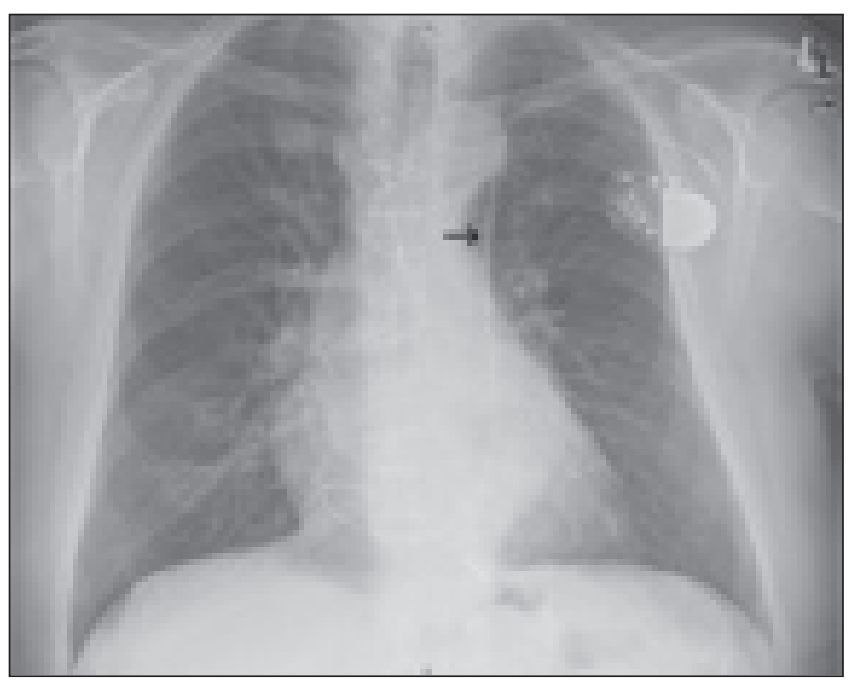

Figure 1) Chest $x$-ray following ventricular rate responsive demand (VVIR) pacemaker implantation, showing a left-sided path of the lead (arrow)

3. Sarodia BD, Stoller JK. Persistent left superior vena cava: Case report and literature review. Respir Care 2000;45:411-6.

4. Rigatelli G. Congenitally persistent left superior vena cava: A possible unpleasant problem during invasive procedures. J Cardiovasc Med 2007;8:483-7.

${ }^{1}$ University Hospital Tübingen, Department of Internal Medicine, Division of Cardiology and Cardiovascular Medicine, Tübingen; ${ }^{2}$ University Hospital Mannheim, Department of Cardiology, Angiology and Pneumology, Mannheim, Germany

Correspondence: Dr Christian S Haas, University of Luebeck, Department of Medicine I, Ratzeburger Allee 160, Luebeck 23538, Germany.

Telephone 49-451-500-5060,fax 49-451-500-5066, e-mail cs_haas@yahoo.com

Received for publication October 15, 2007. Accepted November 10, 2007 